\title{
Art and Technology: Visual Literacy as an Effective Way of Manipulating the Environment
}

\section{Agness Papadopoulou}

\author{
Ph.D., Primary School Teacher, Theatrologist \\ kapitanny@gmail.com
}

\section{Doi:10.5901/mjss.2013.v4n11p50}

\begin{abstract}
'Technology' derives from the Greek word 'TÉXvn'= techni (=art). The term 'technology' could be perceived as a means of control and imposition of man on his natural environment. Moreover, because of technological changes and the success of new products, the processes which reduce the feeling of uncertainty are strengthened. However, human standards secede from man and the equation of living organisms, human societies, systems, concepts is not slow to cast doubt upon the cybernetic control models which manipulate these equations and their natural surroundings. At a time when limits, symbols, associations, experiences no longer stand and the new postmodern world is made up of simulations that are not based on 'reality', visual learning sets constants, since it allows an insight in the perceptual relations of the surrounding forms and the internal structures. According to contemporary neurobiological findings, our everyday life is filled with secondary references to phenomena, while the brain is programmed to process authentic sensory data and compare causalities. In a pixel world, the distinct convention between perceptor and stimulus, signifier and signified does not exist. Art functions in an abstract way, not additionally. The structures of the work of art inform per se and not inductively. Therefore, the way of perception, analysis and use of image is based on a non-verbal neuronal organization.
\end{abstract}

Keywords: Visual Culture, Visual Percepts, Simulacra, Era of Images, Visual Thinking

\section{Project objective}

A point of major importance for this study is the realization that until the mid 20th century and soon afterwards an escape that was not geographical was leading to interesting artistic forms of creation, full of extreme existential tensions; was creating a new art based on great artistic traditions such as Dadaism, in movements such as expressionism, critical realism; an art that was conversing with the history and the soul of a place, of a city on the world map, with people as a physical presence, as viewers. However as of the late 20th century onwards, with the advance of representational mechanisms, we witness an interruption of limits, symbols, associations, experiences, continuity as an escape is intended through the new technologies. Yet this entails the risk that man is nullified within the world of machines, apparatuses, tools.

Edgar Morin states that if we want to see the world correctly, we must watch ourselves watching the world. Today, there is no return to things, the pair of concepts being and appear is not legitimized since we do not start from the forms of things, from their possibilities to be formulated, so as to proceed to the interpretation of the modes of their representations using a methodology -a guide- to comprehend their objective adaptation. In a world of virtual reality, we can not discern similarities, since the reference is not to a realistic or transcendental reality, but to a constructed reality anew in the form of a digital, mathematical model. The real has to be described, not constructed or established, so according to Merleau Ponty, the world is not a matter of a composition, but a natural environment and the field of all thoughts and explicit perceptions of each and every observer.

In antiquity, Murray Peter ${ }^{1}$ (Murray Peter, 1997) argued, the column was perceived as similar to the human body and often in proportion to it. So, the classic building is analogous to the human body. Since then however, and more specifically from the early 20th century, the non-figurative representations of the world (eg K. Malevich) ${ }^{2}$ prevail and as a consequence the level, and thus the man at its center, disappears. Man ceases to be a participant in a fight for the

\footnotetext{
${ }^{1}$ Murray, P., (1997). The Architecture of the Italian Renaissance. Schocken: Rei Sub edition.

${ }^{2}$ Malevich, K., (2003). Suprematism. Guggenheim Museum.
} 
reorganization of the experiential (Sherman W., Craig A., 2002)3; he turns instead to his close ties with machines, not as objects regardless of human nature, but as bonds of the human body with them. Machines are considered artificial extensions of human skill for movement and work, computer keys are an extension of our body. Yet the machine implies a reckoning of the temporary, destruction and death, while the structure is associated with a sense of eternity (Guattari F., 1995) ${ }^{4}$. Today, the tendency is for the manner of interaction with computer not to be defined by keyboards and monitors anymore, but by wireless networks, neural implants. In this way the digital world is incorporated in our daily life, no separation exists.

\section{Introduction}

The new postmodern world is made up of simulations. Baurdrillard discusses the topic of simulation and simulacra that are not based on 'reality'. Virilio disagrees with Baudrillard on the issue of simulation and proposes the term substitution. Virilio believes that there are two kinds of reality: active and virtual reality. The new reality being proposed is the nonmaterial, alongside the existing. Thus, many researchers argue that the disappearance of syntax and semiology and the creation of the absolutely operative formula for everything, for digital, not as a second immaterial reality, but to a grid of capabilities, open up to a universe with limitless potentialities, a simultaneous management of digital and natural space. The focus remains on the main features of virtual environments as open-ended educational environments. Virtual and physical coexist and intertwine. The quality that allows us to be both physically and virtually into a representation is called virtualization.

The excitement for virtual reality is founded on its reshaping of our vision of people and the world we live. Virtual reality will be a place to overcome the natural laws of gravity, a space of projection of the imaginary. This satisfies the interest due to finding new evidence, overcoming the data and participating of the operators of specialized technology without any effort to defend any plausibility, any ambiguous perception of viewers. Holographic images, electronic networks, decorporialisation within the web, complexes and clusterings of data in a non-space of the mind ${ }^{5}$, the user moves as disembodied information. All this could be considered as victories of space and time, echoing a distant desire for a transcendental world, in accordance with the transcendental world of the soul of Plato. It is the replacement of an old historical world of empirical immediacy (Eddings, 1994) ${ }^{6}$, the limits of space and time, with the theories of light and velocity.

In a world like this, the images are attached to the retina of the eye, are implanted in the brain and are perceived as our own. The world of computers, now a tactile world, does not allow the observation and the distance for an understanding of the world. Thus we are talking about a space without considering the body, and subsequently the resistances, the friction, the needs and we translate any feeling or sense in visual subjects. Virtual environments have brought on several devices of new technologies, but the basic direction is for these technologies to be adapted to the human particularities and not vice versa. Bricken says that the essence is inclusion, that the primary defining characteristic of virtual reality is inclusion, being surrounded by an environment ${ }^{7}$. The users have experiences in the virtual environment (Pimentel and Teixeira, 1992) ${ }^{8}$, interacting and changing parameters of this environment.

According to Bartle (2003) $)^{9}$ virtual environments are persistent, because there is a common feeling of space (spatiality), the illusion of presence in the same place (virtuality) (also, see Hamit, 1993) ${ }^{10}$, the common sense of presence, which takes place mostly through anthropomorphic characters (avatars) and that they continue to exist despite the user's non-participation. The comparison is highly interesting between the virtual environments with the communication model of D.Hymes (1967) ${ }^{11}$, the SPEAKING, (S: setting P: participants E: ends K: Key I: instrumentalities $\mathrm{N}$ : norms G: genre). He sought to analyze empirically the discourses through the communicative circumstances in the

\footnotetext{
${ }^{3}$ Sherman, William, \& Craig, Alan, (2002). Understanding Virtual Reality: Interface, Application, and Design. San Francisco: Morgan Kaufmann.

${ }^{4}$ Guattari F., (1995). Chaosmosis: An Ethico-Aesthetic Paradigm. Bloomington Indiana: Indiana University Press.

${ }^{5}$ Hundt, Marianne, Nesselhauf, Nadja, \& Biewer, Carolin (ed.) (2007). Corpus Linguistics and the Web. Editions Rodopi BV.

${ }^{6}$ Eddings claims that the main characteristics of virtual reality are immersion, presence and interactivity. Eddings, J. (1994). How Virtual Reality Works. Ziff Davis Press.

${ }^{7}$ Bricken, William, (1990). Virtual Reality: Directions of Growth. HITL Technical report R-90-1, ftp://ftp.hitl.washington.edu/pub/ publications/papers/m-90-1.html

${ }^{8}$ Pimentel, Ken, \& Teixeira, Kevin, (1993). Virtual Reality Through the New Looking Glass. McGraw Hill Companies.

${ }^{9}$ Bartle, Richard, (2003). Designing Virtual Worlds. New Riders.

${ }^{10}$ Hamit, Francis, (1993). Virtual Reality and the Exploration of Cyberspace. Sams Publishing.

${ }^{11}$ Hymes, D., (1967). Models of the interaction of language and social life. Minneapolis: McNamara.
} 
rituals of primitive societies.

This communicative model proves that the multiple process of communication must be approached in a more global way. Hymes claims that the setting is no "blank space", but that settings reveal experiences, cultural demands, social data of every region and period. Participants with flesh and bones do not wander about, nor are transferred, but they act in a certain place under special circumstances, so the goal/end is not just that the user is not kicked out of the game and 'Game Over!' The keys of action recall some basic themes of the fantastic according to Tzvetan Todorov, such as the distortion of time and space, the dark places of hell, death, the journey to the beyond, the return of the dead. Norms in this chaos, hardly defined, as Sartre says in Nausea that if there is order, what have I to fear ${ }^{12}$. In a state of uncertainty, in a state of constant changes, though, we no longer learn to negotiate lifestyle choices, to give them meaning, but it is impossible to understand and feel the experience of living and the experience of human life, as a setting of desires, conflicts and resistances. The genre today is in danger, since the nature of the human body has been radically modified and its hitherto specific biological limits have been challenged. In the Age of the Images, in a world of screens, the new language is polysemic and not precise, based on the logic of Family Resemblance Theory, a with high demand of emotional response and as far away from the artificial languages of science.

\section{Analysis}

In an age of fluidity, which puts a high premium on a relational character of information, we contradistinguish 'static' conceptions of notions as "stationary" intellectual content, where information is defined as data that are presented in a form directly observable and in which meaning is attributed in the context of their use ${ }^{13}$. That means the hitherto existing educational model is inadequate. The focal point of educational theory and practice is learning how to learn, something that is now technically attainable. Hypermedia - in the meaning of network development- present a knowledge modulated to the person who learns and the concept of link is the key parameter of his culture. This implies a selective, utilitarian information or highly restricted technical skill. The manner in which information is handled becomes highly significant, on it will depend the survival of mankind, since the management of digital information affects the way humans think, construct and experience day-to-day life at a local or global level.

Today the question should be asked why information is transmitted freely in a such a volume globally putting aside sociological, historical differences and addressed to a heterogeneous audience with success. Ambiguity allows 'communality of use' because it facilitates everyone's identification with the subject. The fewer the details, the easier it becomes to see the person displayed as a symbol, a reference concerning everyone, or the display of a leveling logic. The logic of the global village is after all leveling. When no issues of a consensual culture are raised, a hybrid form develops, even if it appears extremely controversial. Manners of a genuinely interactive critique are eliminated and in a world constantly supervised the perceiver is an object of information, never an active subject of communication. Aesthetics is presented as a way of life, as if ceaseless production an end in itself. A universal human fate is predicted or collective human targets are prescribed. We must ask ourselves if we focus on what we see or what we know and also if something captures our attention.

Baudrillard ${ }^{14}$ had described the postmodern condition as a state of affairs where the clearly separate spheres of economy, politics, art and sexuality at the modernist period collapse into another. Moreover, the dream of inseparability between art and life is realized and, according to Baudrillard, with the materialization of art in everyday life art as an isolated and transcendental phenomenon disappears. Baudrillard calls this condition transaesthetics -everything becomes a sign, an image, a spectacle, a transaesthetic object- which he relates to similar phenomena of transeconomics, transpolitics, transsexuality, just as everything also becomes trans-economic, -political, and -sexual, since among various fields of sciences and knowledge the dividing lines are eroded and the boundaries are blurred. The result is a hazy condition where there are no more criteria of value, judgment, or taste, and where the function of the normative thus collapses in a morass of indifference and inertia. And precisely this is the reason why art has become more necessary than ever for the construction of contemporary social order.

If the strong observational criterion is dissolved, then the ethic of the actual fact is introduced as a new ethical issue. Art has fought for a long time to free itself from this ethic using the Aristotelian definition of 'as if'. Especially today that the human experiences of real life have been substituted by the experiences one lives through the digital reconstruction of the most superficial features of life, a need is created to review concepts such as spacetime, matter-

${ }^{12}$ Sartre, Jean-Paul, (2013). Nausea New York: New Directions.

${ }^{13}$ Reitz, Joan, (2004). Dictionary for Library and Information Science. USA: Libraries Unlimited.

${ }^{14}$ Baudrillard, J., (1993). The Transparency of Evil. London: Verso, p.14, 72, 16-19. 
energy, information, virtual, real, intelligence, life and humanity. The new semantic environment requires a corresponding approach in comparison to the monotropic, relatively limited cultural products of the past. The current complex phenomenon of fluxes and formations, which is constantly being transformed in atopic spaces, and also the hybrid entity, the result of the integration of digital imagery in social structures and functions, continuously transform human consciousness and social body.

According to contemporary neurobiological findings, our everyday life is filled with secondary references to phenomena, while the brain is programmed to process authentic sensory data and compare causalities. Humans think well-roundly when there is an equivalent and complementary function of the two hemispheres of the brain. The logicalanalytical classifications, calculations, numbering, details, the conceptualization of individual elements take place in the left hemisphere, while the right hemisphere specializes in the holistic conception of complex situations, relationships, recall, corrects decisions. It uses all elements, such as images, allegory, parable, metaphor, synecdoche, ratio, ambiguity, pun, implicature, paradox, the seemingly absurd, and these exactly are all qualities of modern art. Art allows the discovery of different dimensions of reality, various modes of behavior, distinctive types of personality or social groups ${ }^{15}$ and are included emotional, intuitive and imaginary dimensions in a basically rational process.

In a pixel world the magnitude has changed, because images are magnified to million times their size and pixels are isolated. An excessive focus on isolated settings overturns compactness, where it was expected to be perceived from previous experience. A time delay is possible between the identification of the contour and the function of recognition of compactness. The effect is to upset the whole process that starts by the reception of the percept and ends in the concretion of a concept. The human retina is driven to a training for passive vision. An awareness substitutes the process of consciousness as a result of constantly training the human retina for passive vision. With faint differences and habits we end in a series of generalizations, a Propp's type of logic. The desire to bring things closer and render them manageable destroys the natural way of relating to objects.

Systems consume energy -we know that living systems are open systems, organizational complexes which are far from balanced; Prigozine classifies them in dissipative structures- and only art works precisely as an open field away from the closed concept systems and alienated relationships. In a tumult of aesthetic forms and hedonism -without classical and modernist terms- but with an art as eidolon, artifact, object, simulation or commodity, we should keenly proceed to movements of thawing knowledge and changing the limits of consciousness, attempts to change and defend versus reflexes and visual delusions through advertising, entertainment and market demand. The sensualist education needs to be positioned anew in the intersection of critical pedagogy and political practice. Art is not a commodity and unlike marketable visual results from the entertainment industry, it is preoccupied with the production of endosystemic data, wants to produce the minimum, ie the internal consistency required of art works, so that they can eventually produce a meaning.

The common global pool of culture, information, advertising and entertainment manipulates viewers' gaze so they peep. Let us call this peep shortgaze, because it is weak, blurred or short-circuited. Berger argues that humans have become fully immune to the emotional power of pictures that depict suffering. Pure war in the field of culture is mapped out, according to Virilio, but a visual 'buffer zone' is created, that there is a false distance by the media between war and the rest of us. Sophie Ristelhuber Sophie depicts only places of war, and not participants, craters created by the bombs, burning oil wells, debris in the abandoned battlefield.

The flaws and the gaps between an image and reality will be detected by visual literacy and in reality will positively taken advantage of. One needs to use the inverted mechanism of advertising seduction and the technique of photomontage, such as Martha's Rosler work. Art feeds vision, memory and ultimately consciousness, since art is not consistent with short gaze. Visuality doesn't allow for adhering to outdated ideals, nor to be carried away by the current zeitgeist. Adorno argues that art knows us better than we know ourselves, intensifies processes of self-examination and attempts to try new roles, positions, relationships, ultimately a transformed vision.

\section{Methods}

The construction of any image employs a grammar, a syntax, that is a sequence is constructed with a choice of sizes, equations which establish the concept that is managed by the projected image. Everything is possible through the image, but now with image printing, digital printing, everyone with an image archive, what legislates the creation of the image is the absence of a new language, but the adoption of the common taste and for the impression to be given that everything

\footnotetext{
${ }^{15}$ Green, Maxime, (2000). Releasing the Imagination. San Francisco: Jossey-Bass.
} 
is being committed and everything is repealed. A escapist ethic is a proposed, no need for active thought. Standardized and prefabricated products are offered, market principles are followed to the letter leading to an erosion of authenticity and meaning of social life and also the non-occurrence of broader social goals ${ }^{16}$.

The observation of art works activates reflective thinking. The term 'Sehformen' defined psychologically by Wölfflin as 'forms of beholding' is not simply perceptual readiness, not only requires familiarity, empathy, but homeostatic capacity, homeostasis, an ability that demands persistent training of vision, comparable to that of the artist. We must be fully aware and supervise the special character of art mediums and the internal structural elements of art. Not only a favourable social environment but also the exposure to the arts constitutes protective situations for maintaining homeostasis. Burch ${ }^{17}$ gives a definition of the form in cinema that is both temporal and spacial: The form of a work is that mode of being which ensures its unity while tending to promote, at the same time, the greatest possible diversity. Therefore, art forms enhance the ability of individuals to cope with these stimuli that cause disruption of the sense of well-being.

Perception is a creative process and the aesthetic processes should be assessed by understanding the necessary volume of calculations, as well as the subtle abstract processes that resulted in the aesthetic experience. The technique of triangulation -an imaginary triangle defined by the eyes and the object- provide a way to estimate the size and the position of the object. Visual ability is directly related to the perception of extracorporeal space and mainly its threedimensional (3-D) perception. We humans perceive color in very subjective terms and there are many colours that artists can use in their paintings to increase the sense of space and atmosphere. A painting in vibrant colors activates the brain area V4, such as works of Matice, Bram van Velde, Hans Hofmann etc. In paintings of the Fauves and the Expressionists color becomes a way of seeing. Barnett Newman showed how the amount of autonomous color can be expanded explosively without turning the painting into a decorative object. Color acts as a receptive vehicle, is a means or a material object in the hands of the artist. Rudolf Arnheim argues that the painting focuses more on our sensibilities for the lines, colors and composition than representationality.

The creation of a painterly and emotional space simultaneously, either the artist managing to produce meaningful lines or the line not being there to describe or settle things with the aim of narration -ie it is not there in any way to represent objects belonging to world (see the work of Twombly), therefore either the boundaries between drawing and painting are settled or else merge, the aim being for the visual feelings to penetrate consciousness in a deeper way than the simple act of observation and recording of its findings. The small difference between the data of the pure phenomenological observation, awareness and recording fragments of memory becomes the defining difference between the action of drawing and painting. From the middle to the end of the 20th century the philosophy of the sketch followed the general migratory trend of period, a trend that ultimately affected the consistency of the endosystemic elements of the medium itself, which until then appeared "grosso modo" as compact, but limited as to the potential for autonomy in the area of high art.

The manner in which the artist handles their visual intelligence and makes a decision and not another -ie the preliminary sketches for Picasso's Guernica or how much the landscape at Lake Thun and the surrounding area fascinated artists such as August Macke, Paul Klee and Louis Moilliet in April 1914 in their trip to Tunis- but also the position of the spectators regarding these issues pose questions of attitudes and positions regarding crucial issues touching on life itself. Our familiarity is achieved by the interpretation of complex and controversial issues and the willingness to be receptive to alternative perspectives beyond the given and the mainstream ${ }^{18}$.

Edward Tufte claims that the principles of visual analytical design are universal and not linked to any particular language, culture, style, gender or optical information technology. He explains in detail the six fundamental principles of analytical design: 1. an emphasis on the depiction of comparisons, contrasts, differences, 2. an emphasis on causality, possible underlying mechanisms of similarity and difference, explanation, systematic structure, 3. precise appearance of all the possible multivariate data with more than one or two variables, 4. attentive integration of words, numbers, images, diagrams, 5. thorough description of the evidence, use of detailed titles, substantiation, mention of authors and sponsors, of the data sources, complete measurement scales, pointing out relevant issues, 6 . analytical presentations from which the reception or not of the work depending on the quality, relevance and the integrity of the content is primarily based on. He declares that the purpose of an evidence presentation is to assist thinking and that these six principles of analytical design are derived from the principles of analytical thinking. The request that the art work presupposes is the special observation, the energetic looking at. Visual literacy sets constants since it allows one to indulge in the perceptive

${ }^{16}$ Ritzer, George, (1996). The McDonaldization of Society. California: Pine Forge Press, Thousand Oaks.

17 Burch, N., (1981). Theory of Film Practice. Princeton, N.J.,: Princeton University Press.

${ }^{18}$ Bernstein, J.M., (2006). Voluptuous Bodies: Late Modernism and the Meaning of Painting. Stanford: Stanford University Press. 
relations of the forms around one and the internal structures.

The response to the data of contour, texture, color, full scale and vacuum, the background and the figure and the relations between them, the scale problems, led to the enforcement of the so-called "hard" criteria. The necessity for the existence of criteria such as time, space and their angle of convergence, signals such as form, color, features, deeds, intensity, duration, purpose, are the necessary tools to approach works of art, even if works of art are not representative samples of scenes into the real world, certainly they refer to the real world. So, a reorientation of educational purposes is necessary for all students, in practice, in a real educational environment, an artistic training educational curriculum must be implemented and surely the expected outcome will be very interesting and will bring out a variety of remarkable results. We applied the formalistic model of Karl Aschenbrenner ${ }^{19}$ in students (in the Greek Second Chance School in Kozani, during the years 2008/2009 - 2009/2010 and in Higher Education, in the Technological Educational Institute of Western Macedonia in the academic years 2006/2007 until 2010/2011) and our students developed resistance to sentimental excitations, learned to encode images and use formalistic criteria (criteria of form, of structure, of color) to explore the elements of two types of images (art pictures and utilitarian, such as advertising, mainstream cinema, video games, acute visual reportage, etc.). We developed sets of criteria, criteria of coherence, criteria of clarity, criteria of settings, criteria of proportion, criteria of story line and decoding and deciphering the images' structural elements. A high resolution imaging that almost blurs into the images of mainstream cinema ended in an excellent technical photographic library, to which we are entitled to 'commit sacrilege'. Also, as concerns spatial requirements we examined if a space is a closed or open place, if it is a city or the countryside, if there is difficulty in locating or there is ease respectively, the extent, the continuity, an order, not simply a range, a proximity between any action and the first reaction. As concerns the temporality we studied the duration, the rhythm, the frequency, the continuity, the order, so as to clarify the function of visual percepts as a means of border, as a means of warning or as a medium of discrimination or of orientation, as a means of communication, as a means of learning, as a means of overlapping, as a means of harassment, as a means of identification, or as a medium stimulant or calmative.

The aesthetic experience -particular practices of individual artists, such as in the atlas of visual and mnemonic redesign of Aby Warburg- enhances additional forms of intelligence, such as the kinesthetic, virtual, spatial-temporal, interpersonal, intrapersonal since they process a multitude of symbols and their use, as it becomes possible to express holistic and subtle meanings and also to delineate of emotional states.

\section{Results and Discussion}

Visual learning in the public educational system -such as the work of Addison, Burgess, Steers, Towell- tries to overturn the climate that has been created is so aptly described by a Greek poet, Titos Patrikios, in one of his poems: 'There are small deaths / Secondary amputations: teeth falling, hair, glands function slowly / It is mainly the current sensations that hardly transforms into images' (my translation). This poem is entitled Today's consciousness. Aesthetic functions as way of action and "existence", that means there is no 'direct', no personal experience, but visual percepts depend on forms suggested by advertising, mainstream cinema, video games, etc. A new phenomenon being observed, a strange return of the presumed universality which is based on subjective principles. Today's narratives have solved the fundamental problem that lies in the dilemma of intellectuality and naivety. Tried forms of fairytales, which have no rules and parameters. The story is fantastic, but has common codes. Stories addressed to a global audience, thus it is necessarily to smooth over any differences. Stories are dominated by an exoticism, avoid reality, which has a decorative function. The fighter is confused with someone who consumes his power in agonistic displays. It lacks any sense of proportion of the scale of deeds, so the conflicts conform to these errors of judgement or are adjusted to the absence of any measure. The style and ethos of this constantly revolving stage disguise is cultivated, making easier changes in cultural fields, not to emphasize attempts to smooth progress through social structures autonomous (per se), but as a change imposed from external powers that emerges as a positive strength, so there is no need for any resistance. Adorno claims that form cannot fail to express the crisis, in times where history is in crisis.

The intended purpose is for students to get used to dealing with works of art productively, since art enables them to explore issues and practices, but also to generate knowledge on the school premises, as opposed to the traditional educational techniques of passive reception of knowledge. Till now, the cornerstone of an educational programme is the philosophy of language, which is everywhere and leads to the reproduction of hierarchies in power relations and the setting is used to determine relationships: eg "figure is an index of containing space," and many times, the primary

${ }^{19}$ Aschenbrenner, Karl, (1974). The Concepts of criticism. Dordrecht: D.Reidel. 
"stable" figure is the institution, according to Cornelius Castoriadis ${ }^{20}$, whereas in the pictures of visual art (sculpture, painting etc.) the figure used by itself. A work of art must be accompanied by a condition sine qua non: the absence of functional cause and pronouncement of aesthetic cause. The seemingly neutral indications of where, when, how, what, as elements of everyday life of people, imply a rich and complex stratification of information. Visual literacy offers a new perception to consciousness for familiar surroundings and terra incognita and its topological recordings, eg the characteristic work of Julie Mehretu (Dispersion, 2002, Black Ground, 2006). The composition, the title of the painting in artists such as Kandinsky (Kandinsky ${ }^{21}$ claims that composition is the necessary internally subordination of isolated elements and construction with a specific pictorial view) or Mondrian, seems to signify that their works reflect the very process of their creation. The emphasis is on the use of learning environments outside school, with students participating in debates, exhibitions, activities and on the creation and maintenance of collective social relations, on the interactive and equal communication. In the foregoing analysis we see that these are the prerequisites for achieving any learning goal and one should try to master the heap of visual fragments 'debris' and the excessive production of images.

Visual thinking cultivates the development of communication skills, the ability of expression, self-awareness and empathy as it feeds the reflective imagination. According to Stafford 22 , the ways of learning based on the senses help achieve the transcendence of the limitations of logocentrism and the hierarchies that dominate it, such as read/see, text/ image, mind/body. The most important thing is for students to discover what they want to do, while imagining themselves and how they might do it, on the heuristic problem-positing model of Addison mapping the possibilities of art practice as a mode of research within education (personal training of students, primarily, who are driven to request a special observation that implies the artwork). A commitment between teachers and students that learning is approached through continuous research, with strategies that are changed and redefined in response to each new learning experience. A critical attitude emerges, not so much as concerns the narrative, but the form, which acts as a counterpart of the practice of gaze denial. This acquires the role of a reaction to the emancipation of our gaze from spectacles (eg war as a spectacle) in media. The great contribution of the intelligence of sight and the other ways of learning through our senses strengthen our efforts to survive in post-modern urban receptors (megacities). Visual training acts in opposition to the education of other cognitive fields, and that while the teacher intervenes in an abstractive way, through precisely this release of the image from concepts, we will be able to recognize the difference.

\section{Conclusion}

The basic aim is that students make a resolve to avoid mechanical answers, to clarify terms and concepts without knowing ways of labeling, codifying and deciphering the structural elements of images, in effect without external guidance. Only in works of art is it the case that there are no presupposed key concepts, as in science and artifacts, but art proceeds by presenting a certain inevitability, although this inevitability is not based on objectives. The process of an artwork production involves random movements, risks and danger, but only in the meaning of the composition can modern art be interpreted. An art which serves purposes does not become a mechanism. The gaze "penetrates" the observable form and penetrates additionaly a "hidden" meaning. Seeing is an experience. Virilio said that the field of vision always seemed to him similar to the archaeological field that is ready for excavation. The really interesting pedagogical tool for vision training is the way in which the continuous modification of the basic coordinates in the pictorial space is visualized in a desirable way using the liquidity of the semantic context of the line as an drawing instrument.

Art detects the boundaries of time and space upsetting the borderline of History. The past is activated dynamically through the work of contemporary art, and the postmodern is presented as an affirmation of historical continuity. Besides, the artwork has a cultural value, inevitably connected to the dialectic of history and culture, whether functioning as an affirmation of history or as denier of it. We can only speak for the structural elements of art work, producing qualities in relationships in the perceiver, to construct aesthetic sentences, thereby accomplishing the detachment from the prejudices imposed by the current Zeitgeist. Visual learning, in contrast to the scientific one, functions abstractively, not cumulatively. An object of active perception addresses first the sensory organs, and visual sign systems become comprehensible coming from either computer games or advertising, photography, architecture, art. The aim is to become understandable if in the presented images we can see relations of power and truth, if we recognize the dissolved ego presented as an ideology, as the basis of modern self-preservation and whether these images are ready for

\footnotetext{
20 Castoriadis, C., (2003). The Imaginary Institution of Society. New York: Vintage/Black Lizard.

${ }^{21}$ Kandinsky (1947). Point and Line to Plane. New York: Guggenheim Foundation New York, http://ia700608.us.archive.org/8/items/ pointlinetoplane00kand/pointlinetoplane00kand.pdf

22 Stafford, Barbara, Maria, (1997). Good Looking: Essays on the Virtue of Images. MIT Press, p.21.
} 
consumption, attempting to restore the moral code as desired and cause only facile, rapid affective reaction. The tropistic behavior "stimulus-reflex-response" guarantees a blind obedience to the interests it occasionally serves.

The scale, movement, arrangement, color, perspective, size of the elements in images, line, shape, direction, balance, harmony, contrast, emphasis, parody, simplification, symbolism, inverted image, similarity, the visual relationship in texts, in the foreground, in the background are some examples of visual language: syntax \& semiotics. Images are full of indications of their true structure: it lies in the subtlety, education, the consciousness and the willingness of the perceivers to receive, evaluate, classify them and infer their conclusions.

The predominantly critical dimension of Art achieved through the observation of art works, training of the sensory apparatuses so as to render them more pervasive and more intense, from primary to tertiary education will awake from conceptual languor, editing a comprehensive, integrated pedagogic "ordino" that is based on contemporary neurophysiological data, able to check the immediate affective reactions and it will also allow not only aesthetic evaluation, but will develop a critique against such an unstructured 'wave' of visual information through advertising, the Internet and the entertainment industry. 